\title{
Thermographic proof of 'Flare up syndrome" in patient with allergy to acrylic materials
}

\author{
Evgeni Stanev, Maria Dencheva
}

Faculty of dental medicine, Medical University Sofia, Bulgaria

\begin{abstract}
We report the case of a 23-year-old female dental medicine student with contact dermatitis on her hands caused by methacrylates. Forty-eight-hour closed patch testing showed positive reactions to Ethylenglicol dimethacrylate, 1,6 - Hexanediol diacrylate, 1,4 - Butanediol dimethacrylate, Drometrizole. These are identified as contact allergens. They can be found in the dental materials, but also in the nail polish. It is therefore easy to be exposed to methacrylate in daily life. We measured the skin reaction during the patch test, and noticed that the temperature of the affected skin changes. The highest value was registered when the patches were applied, and the lowest - one week after the treatment.
\end{abstract}

Keywords: Patch-test, thermo-vision, allergic contact dermatitis, methacrylate, professional allergens.

\section{Background:}

The allergic contact dermatitis (ACT) is the most frequent manifestation of immunotoxicity in humans. (1) The disease has a strong social and economic effect .(2) ACT is a the 4-th type reaction by the classification of Coombs and Gell. The allergic reactions that we observed in patch-tests, can be measured by the temperature changes of the affected skin. $(3,4)$ The method we applied to measure the patch test reactions, is also applicable for measurement of the intensity of the allergic reaction of the affected skin.(5) However, some studies show that the local lymph nodes are also involved in the reaction.(6) Initially we assumed that our patient's symptoms are connected with the acrylic products 
contained in her gel nail polish. They can be found in different products like dental composites, nail polish, artificial nails, cosmetics, adhesives, prostheses, etc.(7) There is a similarity between dental and cosmetic products - they have the same kind of methacrylate.(8) In this paper we report a case of contact dermatitis caused by methacrylate contained in different kinds of source - dental materials and cosmetic products.

\section{Case Description:}

We report a case of 23-years old female, student of dental medicine, who developed dermatitis on her hands approximately one month ago, when she applied a nail gel polish in Cyprus - Clarite O.P.I. The gel nail polish is a multicomponent allergen which contains. In the past there were four times of exposure to gel nail polish, but the product have been different. When she was in Cyprus, she visited a dermatologist who put the diagnosis „Allergic contact dermatitis“, and advised the patient to make a patch test. Her hands developed xerotic skin, erythema, papules and itching. When she returns back to Sofia, she starts working with dental materials, mainly with Spophadental - Duracryl ${ }^{\mathrm{TM}}$ Plus. The gel nail polish and the dental materials have some common allergens - Methyl methacrylate, Bisphenol A dimethacrylate, Ethylenglicol dimethacrylate, 1,6 - Hexanediol diacrylate. (8) On figures 1 and 2 we see the affected skin of the palms.

Figure 1. The palms affected by the allergic contact dermatitis

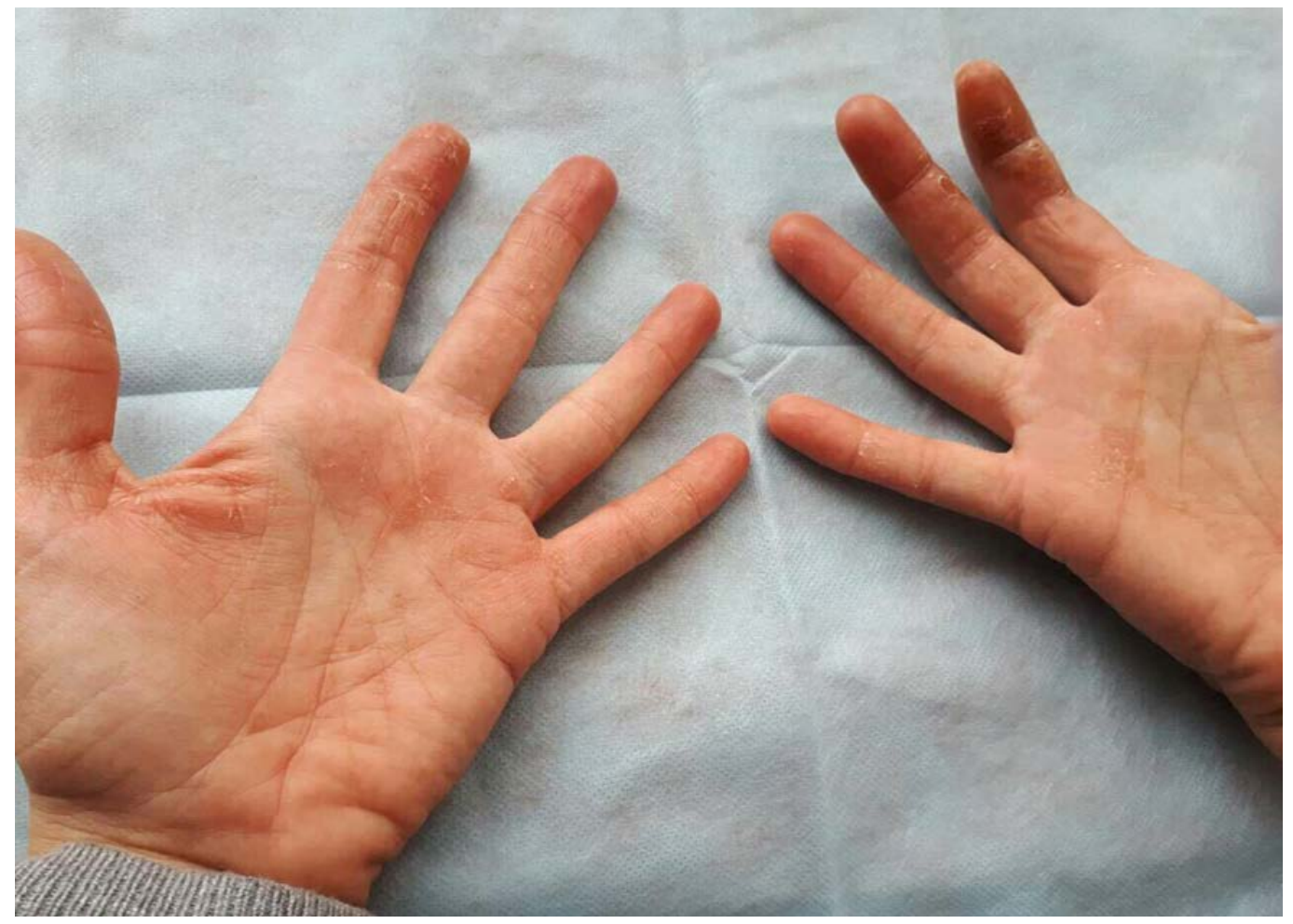


Figure 2. The palms affected by the allergic contact dermatitis.

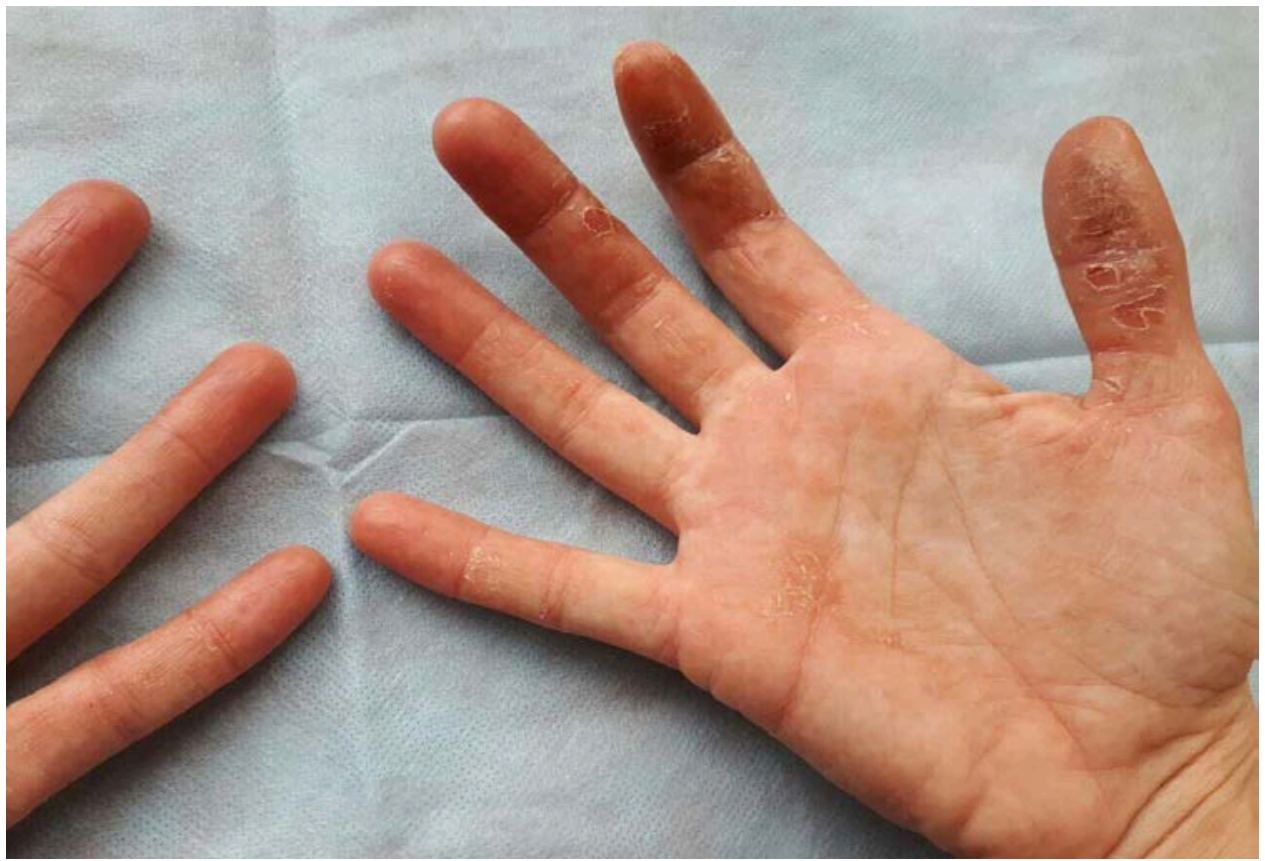

In order to identify the dermatitis cause, we carried out a patch test (on the patient's back) for the most suspicious allergens by the Chemotechnique diagnostics - Dental Screening Series DS-1000, and allergens from the Bulgarian dental allergens produced in the National centre of infectious and parasitic diseases. For patches we use IQ Ultimate ${ }^{\mathrm{TM}}$. The patch test performance and the results assessment were based on the ICDRG (International Contact Dermatitis Research Group) criteria. The results are presented in Figure. 3 in table 1. 
Figure 3. Pictures of the patient's back at the moment of patch test results checking.

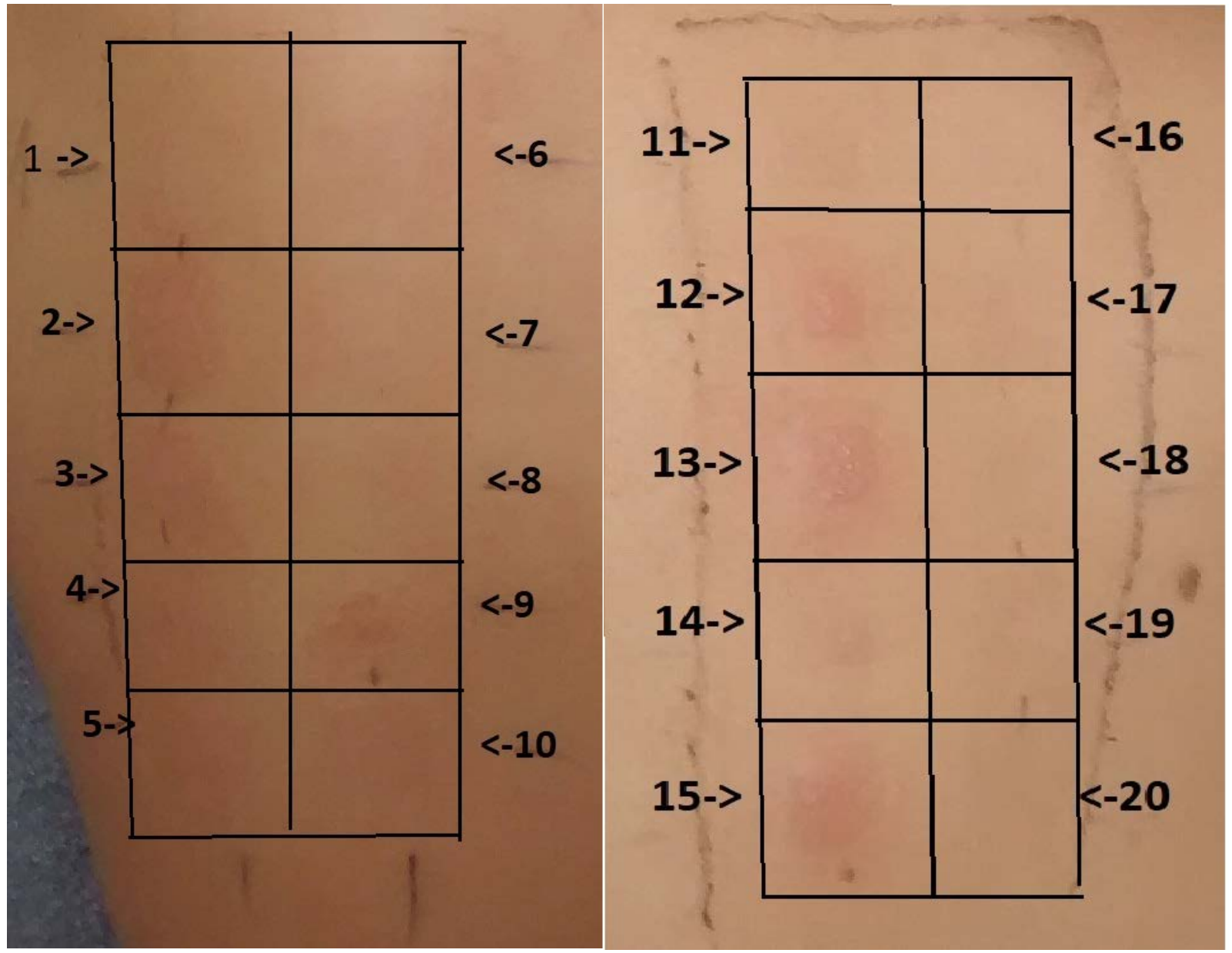

Table 1. Results from the Patch test.

\begin{tabular}{|r|l|l|l|}
\hline No: & Allergen & \multicolumn{2}{l|}{ Reaction } \\
\hline 1 & Natrium lauryl sulfate $0.25 \%$ aq & - & Negative \\
\hline 2 & Nickel $(\mid)$ sulfate hexahydrate $5.0 \%$ pet & + & Positive \\
\hline 3 & Cobalt ( I ) chloride hexahydrate $1.0 \%$ pet & + & Positive \\
\hline 4 & Gold $(\mid)$ sodium thiosulfate dehydrate $2.0 \%$ pet & - & Negative \\
\hline 5 & Potasium dichromate $0.5 \%$ pet & - & Negative \\
\hline 6 & Bisphenol A dimethacrylate $2.0 \%$ pet & - & Negative \\
\hline
\end{tabular}


I S S U E 2,2018

\begin{tabular}{|r|l|l|l|}
\hline 7 & Tetrahydrofurfuryl methacrylate 2.0\% pet & - & Negative \\
\hline 8 & Mercury 0.5\% pet & - & Negative \\
\hline 9 & Methyl methacrylate $-2.0 \%$ pet & - & Negative \\
\hline 10 & Negative control (empty chamber) & - & Negative \\
\hline 11 & $\begin{array}{l}2,2 \text {-bis(4-(2-Methacryl-oxyethoxy)phenyl)propane } \\
(\text { BIS-EMA) 2.0\% pet }\end{array}$ & - & Negative \\
\hline 12 & Ethylenglicol dimethacrylate 2.0\% pet & ++ & Positive \\
\hline 13 & $1,6-$ Hexanediol diacrylate 0.1\% pet & +++ & Positive \\
\hline 14 & $1,4-$ Butanediol dimethacrylate 2.0 \% pet & + & Positive \\
\hline 15 & Eugenol 2.0 \% pet & +++ & Positive \\
\hline 16 & Colophonum 20 \% pet & - & Negative \\
\hline 17 & Drometrizole 1.0 \% pet & + & Positive \\
\hline 18 & Camphoroquinone (Bornanedione) $1 \%$ pet & - & Negative \\
\hline 19 & Palladium ( II) chloride 2.0 \% pet & - & Negative \\
\hline 20 & Carvone 5.0 \% pet & - & Negative \\
\hline & & \\
\hline
\end{tabular}

We have positive reactions for two of the common allergens: Ethylenglicol dimethacrylate and 1,6 Hexanediol diacrylate.

I order to assess the allergic inflammation status we measured the temperature of the affected areas three times: before the patch test; on the day when we read the result; and one week later. These measurements were performed with FLIR T620 thermo-camera with resolution 0,06 degrees and software Flir Reporter Professional software 2013. We accept for significant any temperature change for more than 0.4 degrees between first and last monitoring of identical areas of the skin. The thermovision is performed in a special room for this in the Faculty of dental medicine - Sofia. The temperature there is $22+/-2$ degrees, the humidity $40 \%$, no movement of air with more of 1.0 meters $/ \mathrm{sec}$, distance between the camera and the patient from 0.3 to 2 meters, no thermal radiation open sources. (9) The temperatures we detected are summarized in table 2. On Figure 4, 5 and 6 we show the thermos-vision pictures of the hands. Figures 7 and 8 present a comparison between the temperatures of the different fingers and Figure 9 - the average temperatures of the three measurements. 
Figure 4. Thermo-vision picture of the hands before the patch test.

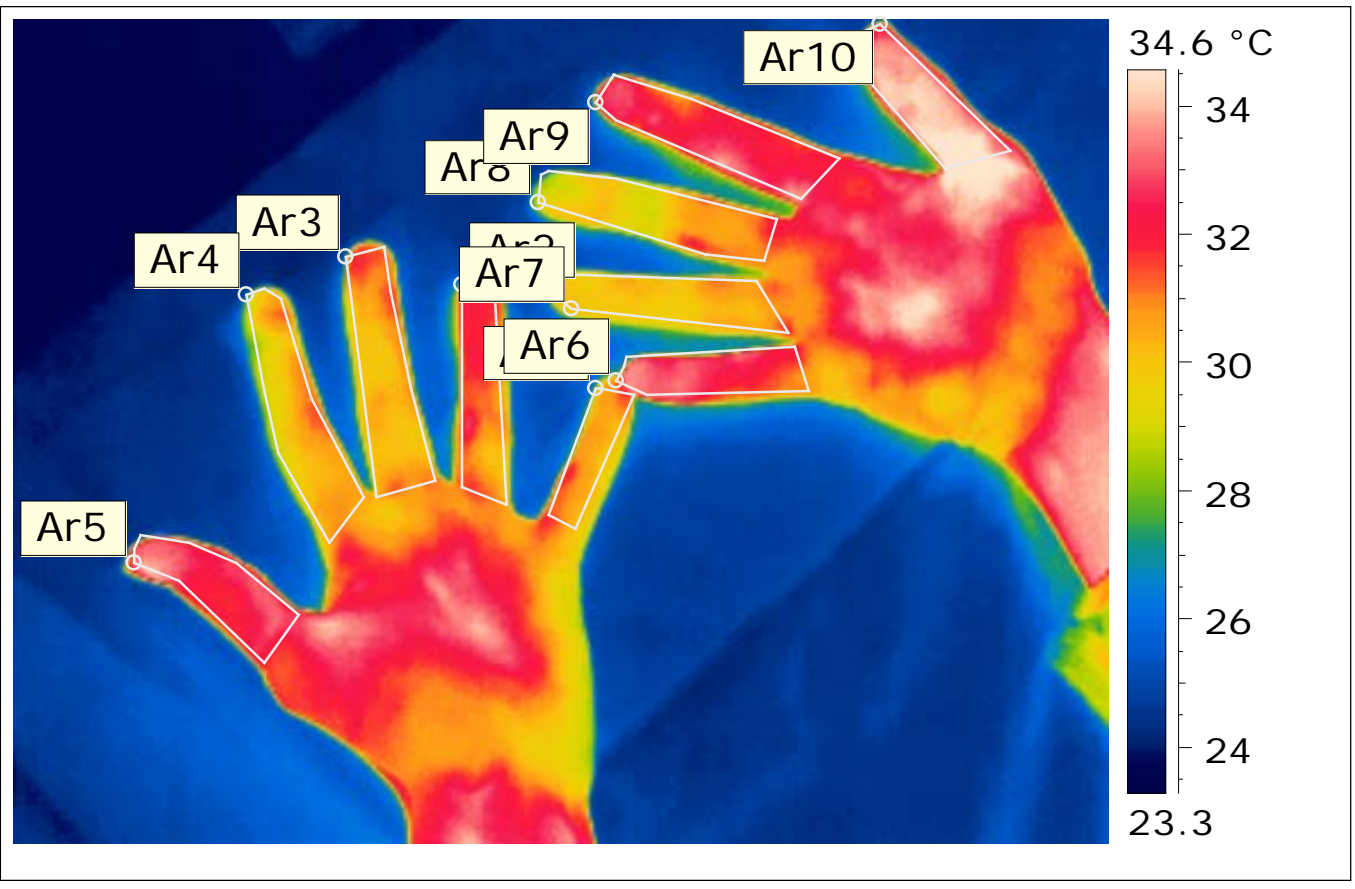

Figure 5. Thermo-vision picture of the hands in the day of the patch test reading.

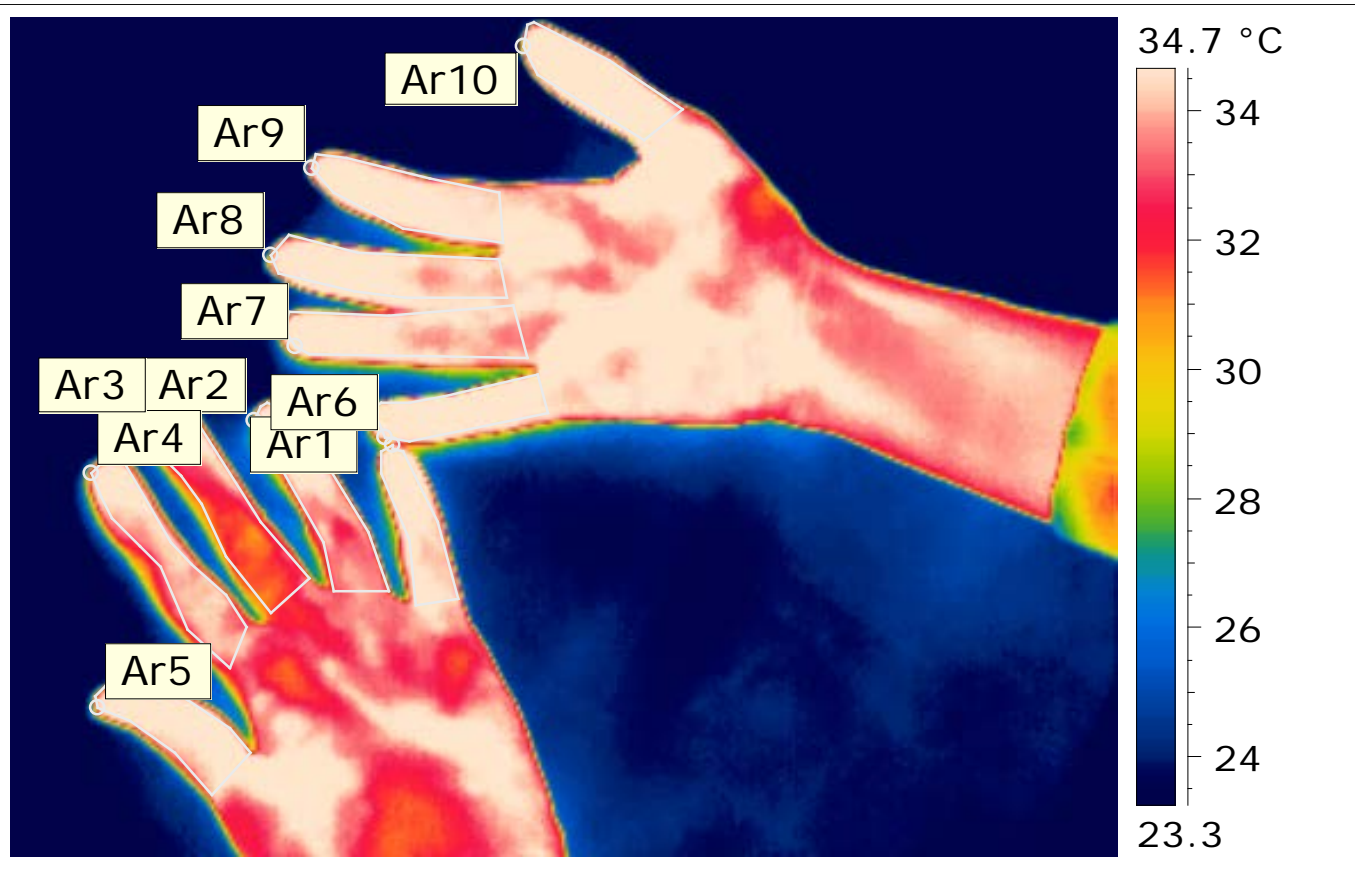


Figure 6. Thermovision picture one week after the beginning of the treatment.

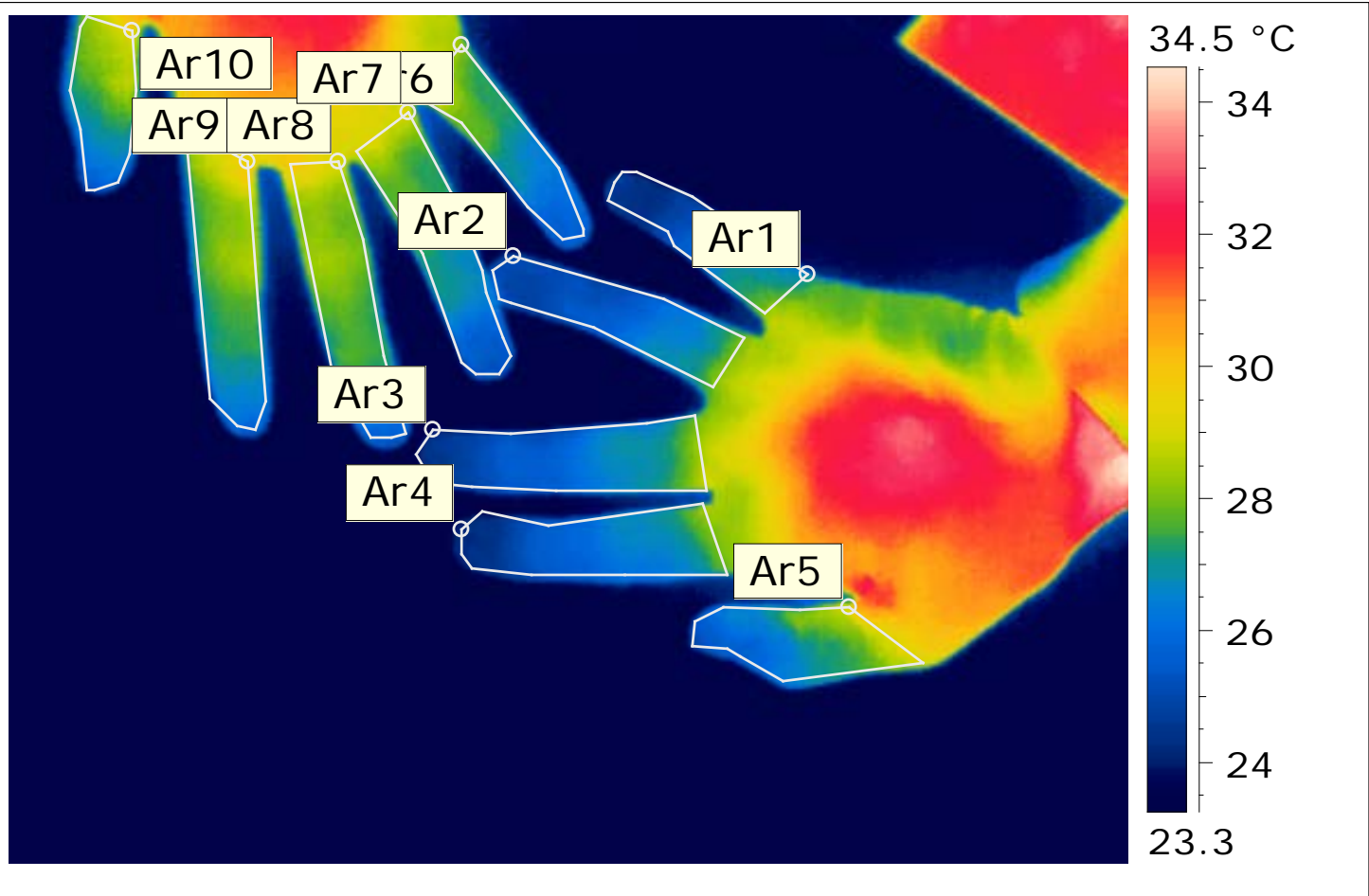

About 8 hours after the patch application, the patient called to complain from strong itching on the place of the patch, and perioral rash. Later she visited our laboratory for patch reading, and by this time the rash had disappeared.

Treatment: The patient was informed the sources of allergens, and advised to stop any contact with them. The nail polish was removed carefully, and the contact with dental materials containing methacrylate was avoided. We prescribed a topical corticosteroid cream - Elocom - $0.1 \%$ and another cream containing urea - Linola ${ }^{\circledR}$ Urea $12 \%$. 
Table 2. Maximal and average temperatures of the affected areas.

\begin{tabular}{|l|r|r|r|}
\hline & $\begin{array}{l}\text { Before the } \\
\text { patch test }\end{array}$ & $\begin{array}{l}\text { After the } \\
\text { patch test }\end{array}$ & $\begin{array}{l}\text { One week } \\
\text { later }\end{array}$ \\
\hline Max Temperature & 35.8 & 36.4 & 34.6 \\
\hline Min Temperature & 23 & 20.3 & 21.7 \\
\hline Image Max. Temperature & 35.8 & 36.4 & 34.6 \\
\hline Ar1 Max. Temperature & 32.1 & 35.6 & 28.5 \\
\hline Ar10 Max. Temperature & 35.8 & 36.2 & 29.5 \\
\hline Ar2 Max. Temperature & 32.9 & 35.6 & 28.4 \\
\hline Ar3 Max. Temperature & 31.8 & 35.1 & 29 \\
\hline Ar4 Max. Temperature & 31.5 & 35.4 & 28.4 \\
\hline Ar5 Max. Temperature & 34 & 35.6 & 30 \\
\hline Ar6 Max. Temperature & 33.7 & 36.2 & 29.3 \\
\hline Ar7 Max. Temperature & 31.7 & 35.7 & 29.1 \\
\hline Ar8 Max. Temperature & 32.3 & 35.6 & 29.9 \\
\hline Ar9 Max. Temperature & 34 & 36 & 30 \\
\hline Ar1 Average Temperature & 30.6 & 34.8 & 25.8 \\
\hline Ar10 Average Temperature & 33.9 & 35.3 & 27.5 \\
\hline Ar2 Average Temperature & 31.2 & 34 & 26 \\
\hline Ar3 Average Temperature & 30.5 & 32.5 & 26.1 \\
\hline Ar4 Average Temperature & 30.2 & 34.1 & 26 \\
\hline Ar5 Average Temperature & 32.5 & 34.8 & 27.1 \\
\hline Ar6 Average Temperature & 32.2 & 35.2 & 27.1 \\
\hline Ar7 Average Temperature & 30.2 & 34.5 & 27.1 \\
\hline Ar8 Average Temperature & 30.2 & 34.6 & 27.7 \\
\hline Ar9 Average Temperature & 32.2 & 34.9 & 27.7 \\
\hline
\end{tabular}


Figure 7. Maximal temperatures of the explored areas.

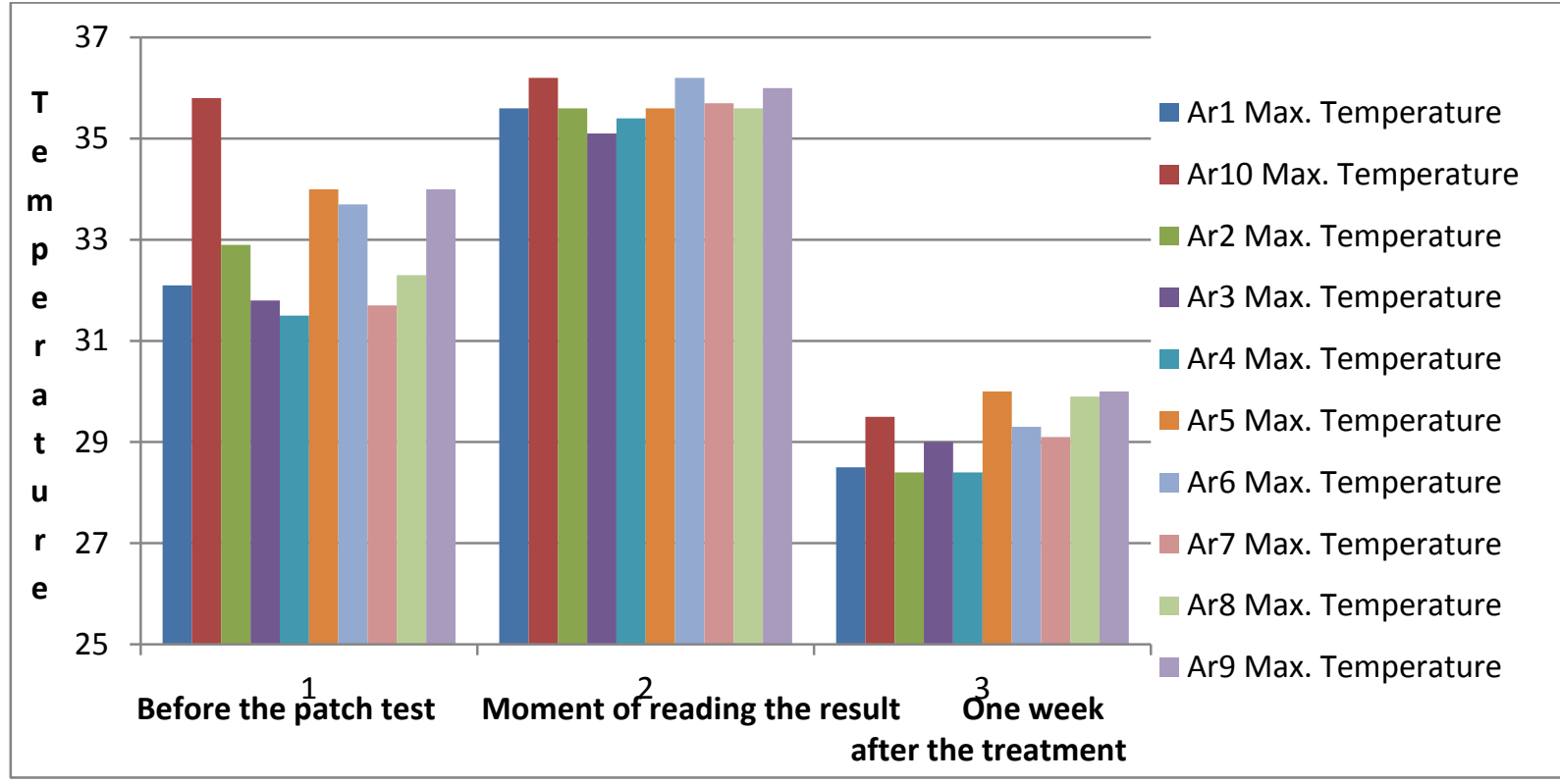

Figure 8. Average temperatures of the explored areas.

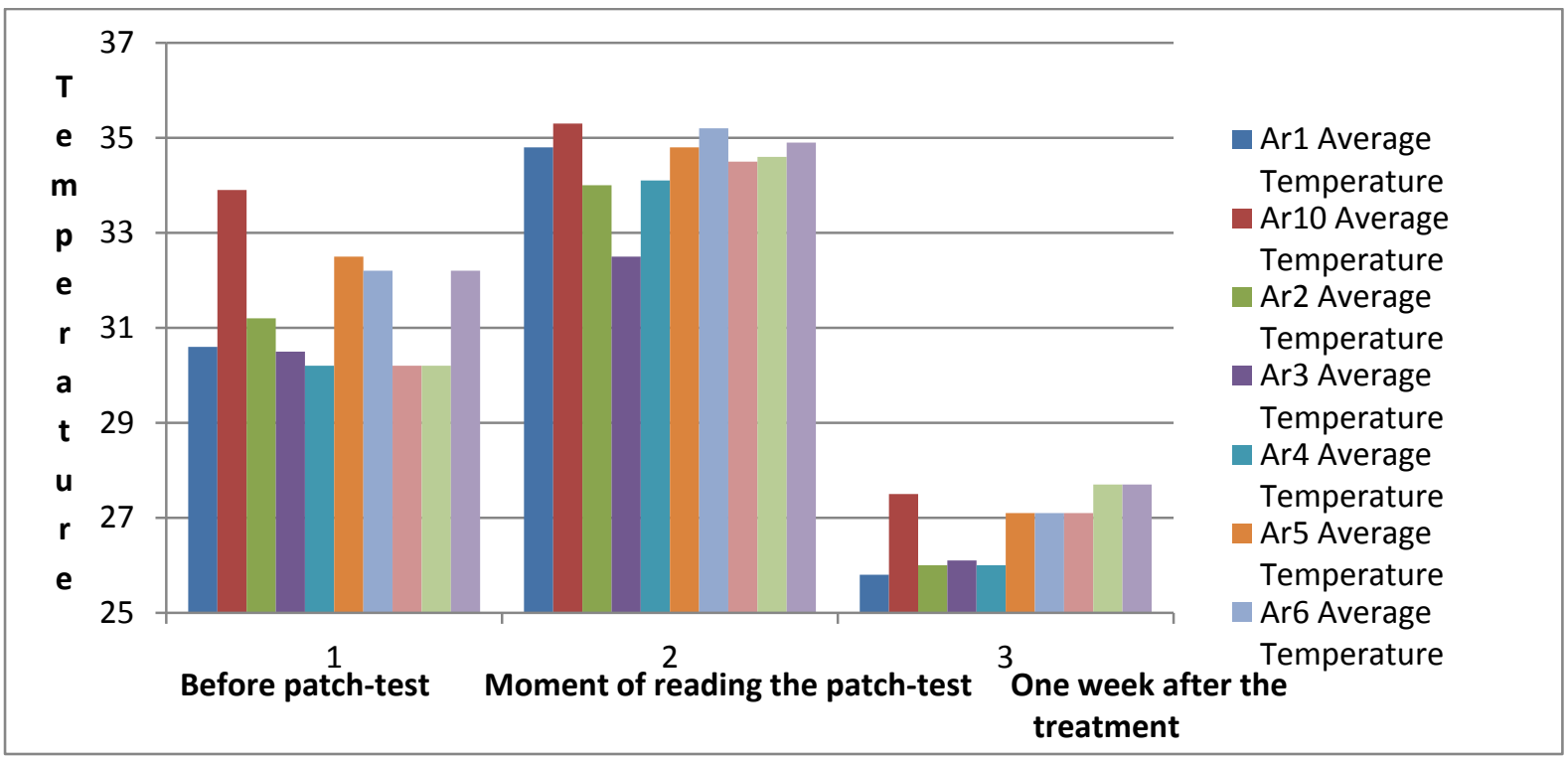


Figure 9. The change of the maximal and average temperature at the three moments of measurement.

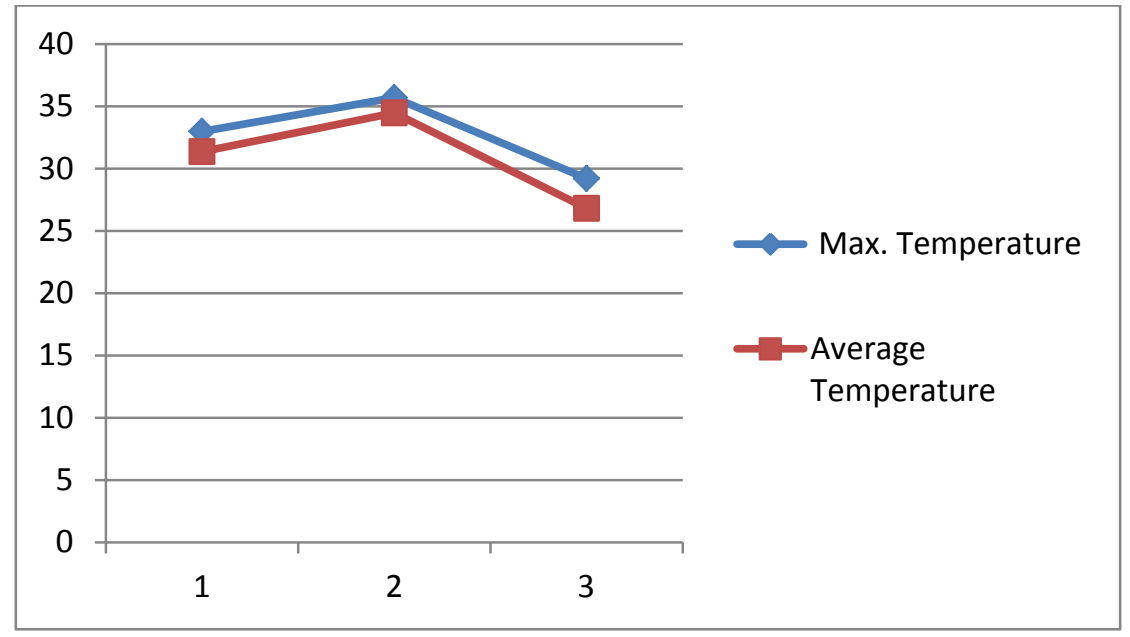

Figure 10. The palms of the patient one week after the last contact with the allergens.

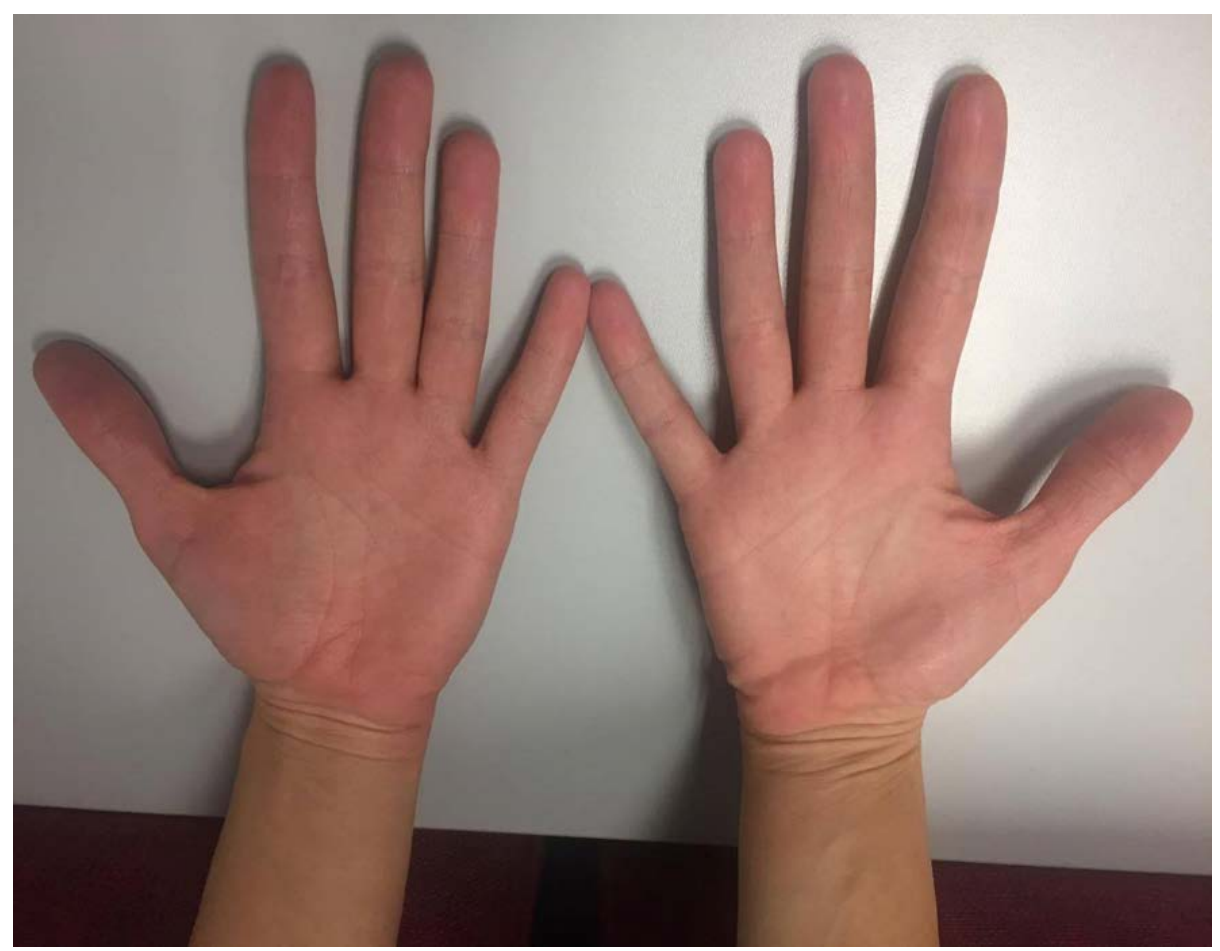




\section{Discussion}

The patch test makes contact between the skin and allergens. Our aim was to provoke an allergic reaction, that would indicate sensibilisation of the organism. The sesibilisation to acrylic monomers is often observed in dental personal, and our patient is working with dental materials during her education. $(10,11)$ Besides, there are cases of contact dermatitis induced by the methacrylate contained in artificial nails. (12) We also have to consider the full range of responses observed during the patch test. This includes the possibility that the results could be a result of cross reactivity or more likely a broad increase in sensitivity to all allergens as a result of compromised skin barrier condition as is a well-recognised phenomenon in dental industry. $(13,14)$

We presume that the process has a local character. However, the impact area and borders are subject of discussion. The allergic reactions are functions of the immune system, so we can expect the whole immune system to be involved. This means that the test affects the whole organism. On the other hand, the reactions of this type is relevant to the local effects of the allergens in the place of contact. This is demonstrated by the observed skin changes.

However we noticed increasing of the intensity of the main allergic disease - demonstrated by increase of hands temperature.

\section{Conclusion}

We analysed the thermovision photographs to estimate the intensity of the allergic inflammation. The temperature trend of the affected areas indicates how the disease develops. As a component of the inflammation, the rising of the temperature is a sign of exacerbation. This risk of exacerbation has to be considered every time when a patch test is performed.

\section{References}

1. Kimber I, Basketter DA, Gerberick GF, et al. Allergic contact dermatitis. International immunopharmacology 2002;2:201-211.

2. Uter W, Schnuch A, Geier J, et al. Epidemiology of contact dermatitis. The information network of departments of dermatology (IVDK) in Germany. European journal of dermatology: EJD 1998;8:36-40.

3. Dencheva M, Lyapina M, Kisselova-Yaneva $A$ et al. Thermovision in dental allergology. Journal of IMAB-Annual Proceeding Scientific Papers 2014;20:558-562.

4. Laino L, Di Carlo A. Telethermography: an objective method for evaluating patch test reactions. European Journal of Dermatology 2010;20:175-180.

5. Di Carlo A. Thermography and the possibilities for its applications in clinical and experimental dermatology. Clinics in dermatology 1995;13:329-336.

6. Kimber I, Hilton J, Botham PA. Identification of contact allergens using the murine local lymph node assay: comparisons with the Buehler occluded patch test in guinea pigs. Journal of Applied Toxicology 1990;10:173-180.

7. Chemotechnique diagnostics - Patch Test Products \& Reference Manual 2018 https://www.chemotechnique.se/ 
8. Chonin AS. Allergy to metacrylates in dental medicine. PhD thesis. Plovdiv 2017

9. Dencheva M, Balcheva M. Dental Clinical Allergology for dental students. Publisher: Za bukvite 2014 book.

10. Aalto-Korte K, Alanko K, Kuuliala O, et al. Methacrylate and acrylate allergy in dental personnel. Contact dermatitis 2007;57:324-330.

11. Kiec-Swierczynska M. Occupational allergic contact dermatitis due to acrylates in Lodz. Contact Dermatitis 1996;34:419-422.

12. Marks JG, Bishop ME, Willis WF. Allergic contact dermatitis to sculptured nails. Archives of dermatology 1979;115:100.

13. Lazzarini R, Hafner MD, Lopes AS, et al. Allergy to hypoallergenic nail polish: does this exist? Anais brasileiros de dermatologia 2017;92:421-422.

14. Douwes J, Slater T, Shanthakumar M, et al. Determinants of hand dermatitis, urticaria and loss of skin barrier function in professional cleaners in New Zealand. International journal of occupational and environmental health 2017;23:110-119.

\section{Corresponding author:}

Dr. Evgeni Stanev,

Faculty of dental medicine,

Medical University.

str. "Georgi Sofiyski” №1,

Sofia, Bulgaria

Tel: +3599888 11648

email: stanev242@gmail.com 